\title{
CO-TEACHING WITHIN DIVERSITY: A DISRUPTIVE PRODUCTIVE SOURCE OF PROFESSIONAL DEVELOPMENT
}

\section{Jeannin*}

Faculty of Education

e-mail: loisej@uj.ac.za

\author{
N. Sing* \\ Faculty of Education \\ e-mail: nevensha.sing@gmail.com
}

*University of Johannesburg

Johannesburg, South Africa

\section{ABSTRACT}

This self-reflective study explores how culturally diverse faculty members can benefit from coteaching in higher education classes. It reflects on a teaching collaboration between two researchers-practitioners from different cultural and academic backgrounds in a South African university. The co-teachers shared equal responsibility for a one-month research seminar. The leading argument of this article is that co-teaching within diversity is a key driver for disruptive and productive professional development, as co-teaching exposes faculty members to pedagogical activities and discourses they would not otherwise have experienced. It enables them to move beyond their comfort zone, take risks collectively, and learn reciprocally. The qualitative findings are organised in a model that conceptualises the co-teaching process, unpacking the relationship between empowering trust, emerging complementarities, reciprocal learning, and professional identity affirmation. The model can help teachers reap the benefits of co-teaching in culturally diverse environments.

Keywords: co-teaching, university teaching, faculty professional development, diversity, collegiality, reciprocal learning

\section{INTRODUCTION}

The diversity of faculty members in higher education institutions pertains to their various experiences, but also to their diverse socioeconomic, academic, and linguistic backgrounds. This diversity is widening through the increasing trend of academic staff mobility at global and regional levels. For example, the Southern African Development Community (SADC) encourages academic staff mobility within the region. The growth of North-to-South and Southto-South academic exchanges enables African universities to host an increasing population of international faculty members. It provides an opportunity for collaboration between host and 
international academics, enabling them to grow from their diverse competencies and perspectives (Brooks and Brooks 2015; Dunn and Wallace 2008; Spencer-Oatey 2013). Therefore, host universities in South Africa seek to reap the benefits of their increasingly diverse academic staff and students by encouraging faculty collaboration in research and teaching projects (Jowi 2012; Rouhani 2007; Cross, Mhlanga and Ojo 2009).

In order to benefit from the internationalisation of their academic staff population (Tadaki and Tremewan 2013), some universities prompt international academics to contribute to the development of effective pedagogical practices and the cogeneration of knowledge. Faculty collaboration is expected to generate new ideas and practices (Martin-Beltran and Peercy 2014; Graziano and Navarrete 2012) as host and international lecturers can intersect their diverse practices, experiences and conceptions of realities (Dunn and Wallace 2008; Spencer-Oatey 2013). Teachers coming from distinctive cultural backgrounds have been socialised in different educational systems, and their teaching philosophy and practices are more likely to differ compared to teachers hailing from the same country (Merriam and Kim 2011). For example, the conceptions of culturally diverse lecturers regarding their expected roles and the proper interactions between students and teachers vary (Kainzbauer and Hunt 2014; Ma 2014; Merriam and Kim 2011). Sharing their diverse points of view, lecturers can widen their perspectives and understanding, in other words, interfacing their conceptions of reality (Lai, Li and Gong 2016; Mizzi 2017).

Host and international faculty collaboration is expected to contribute to staff development as teachers can learn mutually from their distinctive paradigms (Plank 2011; Shaffer and Thomas-Brown 2015; Spencer-Oatey 2013). There is a paucity of research on the benefits and complexity of academic staff collaboration in culturally diverse universities (Spencer-Oatey 2013; Lai, Li and Gong 2016; Martin-Beltran and Peercy 2014), but there is even less research on how co-teaching benefits in practice from a context of cultural diversity. This study addresses this gap and engages with the complexity of a collaborative project between two culturally diverse faculty members in a South African university. It scrutinises the co-teaching experiences of the two participants using a self-reflective approach.

In addition to contributing to the discourse on cross-cultural academic collaboration, this study is significant in the South African context of universities' internationalisation, revitalisation, and decolonisation (Cross, Mhlanga and Ojo 2009; Kishun 2007; Le Grange 2016). Host and international academic staff collaborations can offer opportunities to regenerate knowledge at South African universities through constructive dialogues. In conceptualising the multiple negotiations and pedagogical repositioning that result from co- 
teaching, we aim to explore the benefits of such collaboration for culturally diverse protagonists.

In the literature, diverse forms of co-teaching have been identified depending on the distribution of roles among teachers (Cook and Friend 1995). These diverse roles encompass one teach-one observe, one teach-one assist, but also parallel teaching whereby lecturers teach the same content to two classes in parallel, and team teaching qualifying situations where instructors teach the same course together (Cook and Friend 1995). To inform our study, we drew on the literature on team teaching that Hurd $(2016,1)$ defined as "well planned, teamtaught lessons that exhibit an invisible flow of instruction with no prescribed division of authority”.

A team-teaching arrangement was logical for us as we wanted to equally contribute to the seminar in such a way that would enhance students' learning experiences (Martin-Beltran and Peercy 2014). Despite our different academic and cultural backgrounds, we shared responsibility for the course preparation and delivery, and we situated ourselves as equally knowledgeable and competent. Our relationship was therefore driven by a shared goal and built upon reciprocal accountability and trust. This team teaching arrangement also helped us preempt the risk of power-related conflicts (Ferguson and Wilson 2011). In this article, we examine our experiences of co-teaching and analyse how our cultural and background differences have impacted on our experiences. The research questions informing our reflections were:

- How do we retrospectively conceptualise the co-teaching experience within diversity?

- How did we grow professionally from this co-teaching experience?

The article begins with a review of literature on the benefits and challenges of co-teaching in a context of academic and cultural diversity. Following a presentation of the conceptual framework, the article details the methodology used to analyse our journal entries. Qualitative findings are used to conceptualise the co-teaching relationship in a model of co-teaching within diversity. This model is organised around the links between empowering trust, the operationalisation of teachers' complementarities, reciprocal learning, and professional identity affirmation. We finally argue that co-teaching between culturally diverse teachers is a disruptive and productive source of professional development as it encourages faculty members to venture beyond their comfort zone and strengthen their sense of self-competency. 


\section{CO-TEACHING WITHIN DIVERSITY: INSIGHTS FROM THE LITERATURE}

What follows is a mapping of the literature discourses on co-teaching in culturally and academically diverse contexts and the pros and cons thereof. As the literature on the relationships between international exposure and professional development is gaining importance (Smith 2009; Dunn and Wallace 2008; Volet and Jones 2012), we focus in this review on the specificities of co-teaching in a context of cultural and discipline diversity. As there are different ways to co-teach, we prioritised the literature covering team-teaching arrangements when both lecturers shared equally the course responsibility and ownership. The literature search was conducted systematically using the following key terms: (university) coteaching, (cultural/academic/discipline) diversity, (host/international) faculty collaboration, internationalisation, and co-teaching challenges.

\section{The benefits of co-teaching for diverse teachers}

Co-teaching in a context of mutual respect for diversity has been praised for reciprocal learning (Graziano and Navarrete 2012; Martin-Beltran and Peercy 2014; Plank 2011) but also as a factor of job satisfaction and increase in motivation (Birrell and Bullough Jr. 2005). Many teachers across different countries and disciplines reported feeling energised and reinvigorated as a result of co-teaching (Plank 2011; Graziano and Navarrete 2012). Analysing their experiences in an American college, Graziano and Navarrete (2012) revealed how co-teaching between lecturers with different teaching philosophies created opportunities for clarifying ideas during the content preparation phase. Graziano and Navarrete (2012) reported spontaneous collaboration in class bringing about pedagogical " $a$ ha" moments and reciprocal learning. They explained how it energised them to further deepen their pedagogical knowledge, but also emphasised that co-teaching required time, flexibility, and compromise.

Another benefit of co-teaching emphasised in the literature is the opportunity for perspective shifts. Working as dialogue partners, culturally and academically diverse coteachers can engage with different teaching and learning styles (Encabo 2015; Luke and Rogers 2015; Tremblay 2015). The negotiation of content, teaching philosophies, and delivery methods in the preparation phase enable lecturers to widen their understanding of the scope of pedagogical practices and philosophies that are used in different countries (Encabo 2015; Graziano and Navarrete 2012).

Co-teaching from different cultural backgrounds is beneficial for both host and international lecturers under the conditions of accommodating diverse viewpoints and avoiding the imposition of a particular teaching approach on one's colleague. This raises the question of 
agency in international collaboration. Through interviews with 14 Chinese language teachers in international schools in Hong-Kong, Lai, Li and Gong (2016) unpacked the role of agency in professional learning. They analysed how the participants, who were language teachers from a minority group, exerted their agency to adapt, learn, and to a lesser extent, contribute to pedagogical changes in their host institutions. Lai, Li and Gong (2016) showed how the minority teachers ended up adopting their host colleagues' instructional practices rather than modifying the site teaching practices. As a result, the authors urged organisations to better include foreign or visiting lecturers and encourage them to contribute to the site improvements.

As co-teaching can generate productive collaborations between host and international faculty members, it can nevertheless create a range of challenges around the issues of power negotiation, status recognition, and cross-cultural communication (Brooks and Brooks 2015; Ferguson and Wilson 2011; Hersi, Horan and Lewis 2016; Spencer-Oatey 2013). Co-teaching is a dynamic relationship that engages teachers cognitively and emotionally in the preparation and delivery of the class (Plank 2011). It thus entails inherent risks of conflicts that are heeded in the following subsection.

\section{The hurdles of co-teaching within diversity}

We focus in the following section on the co-teaching difficulties reported in the literature with a special emphasis on contexts of diversity. Due to the differences in word meanings, misunderstandings can easily arise in cross-cultural environments as communication styles and teaching-learning preferences differ (Brett, Behfar and Kern 2006; Brooks and Brooks 2015; Mizzi 2017). English words do not necessarily hold the same meaning from one country to another, and it can create confusion when both parties think they understood each other, but realise later they did not (Brooks and Brooks 2015). In addition, the communication cues used by host and international academic staff may not carry the same message (Brooks and Brooks 2015; Spencer-Oatey 2013; Brett, Behfar and Kern 2006). Hence, it requires all stakeholders to clarify the meaning of words and the objectives of the collaboration, but also to achieve mutual clarity on the implicit expectations of both parties. If the terms of the collaboration are not clearly negotiated in advance, misconceptions can easily jeopardise the trust relationship between both parties.

Teachers from different backgrounds do not necessarily share the same teaching philosophies, goals, and habits (Mizzi 2017; Spencer-Oatey 2013). Difficulties in preparing and co-teaching the class, but also in assessing and grading students effectively, can ensue from the diversity of perspectives (Ferguson and Wilson 2011). Similarly, the conflicting pace of 
instruction, disruptive interventions in class, and inequality in the teaching time allocation can easily affect the trust relationship between co-teachers.

Other potential sources of conflict that are not specifically related to cultural diversity could include a clash of personalities, inadequate organisational and managerial culture in the institution, a lack of organisation flexibility to permit co-teaching, and a lack of professional ethics (Hersi, Horan and Lewis 2016). In addition, feelings of inadequacy, fear of judgment, and competition for status recognition can hinder the co-teaching relationships (Ferguson and Wilson 2011; Hersi, Horan and Lewis 2016; Hsieh and Nguyen 2015). These difficulties should be taken into account to unravel the full complexity of collaborative relationships even though they do not arise solely from the background diversity of the protagonists.

As for all collaborative projects in multicultural settings, conflict resolution skills are pivotal to reconcile divergent perspectives (Graziano and Navarrete 2012; Brett, Behfar and Kern 2006). Teachers holding different teaching philosophies, habits, and expectations will have to compromise. Hence, culturally responsive communication efforts are crucial, especially from the beginning of the co-teaching journey to develop a trusting and caring relationship and dismantle the risks of power competition, fear of judgement, and suspicion (Spencer-Oatey 2013; Brooks and Brooks 2015). Open communication, shared goals, effective preparation, professional ethics, and flexibility can help teachers actualise the learning potential of coteaching and move away from a competitive conception of team teaching (Ferguson and Wilson 2011; Tschannen-Moran 2014). We subsequently drew on the insights of this literature review to develop our conceptual framework.

\section{CONCEPTUAL FRAMEWORK}

In thinking about how to work and co-teach together, we developed a framework informed by the literature. Being a point of departure, the conceptual framework (Figure 1) illustrates the core relationship of an effective collaborative project. This initial model was used for hypothesis testing (Lodico, Spaulding and Voegtle 2010), and was subsequently refined in regard of our data to design the model presented in the findings.

A sound co-teaching relationship is rooted in reciprocal trust. Trust is derived from mutual respect, willingness to share, reliability, and competency (Brooks and Brooks 2015; TschannenMoran 2014). We contend that trust empowers collaborators as they feel supported by their peers and become more likely to share their distinctive expertise. Therefore, empowering trust enables teachers to share their professional capital throughout the process of collaboration (Cranston 2011). 


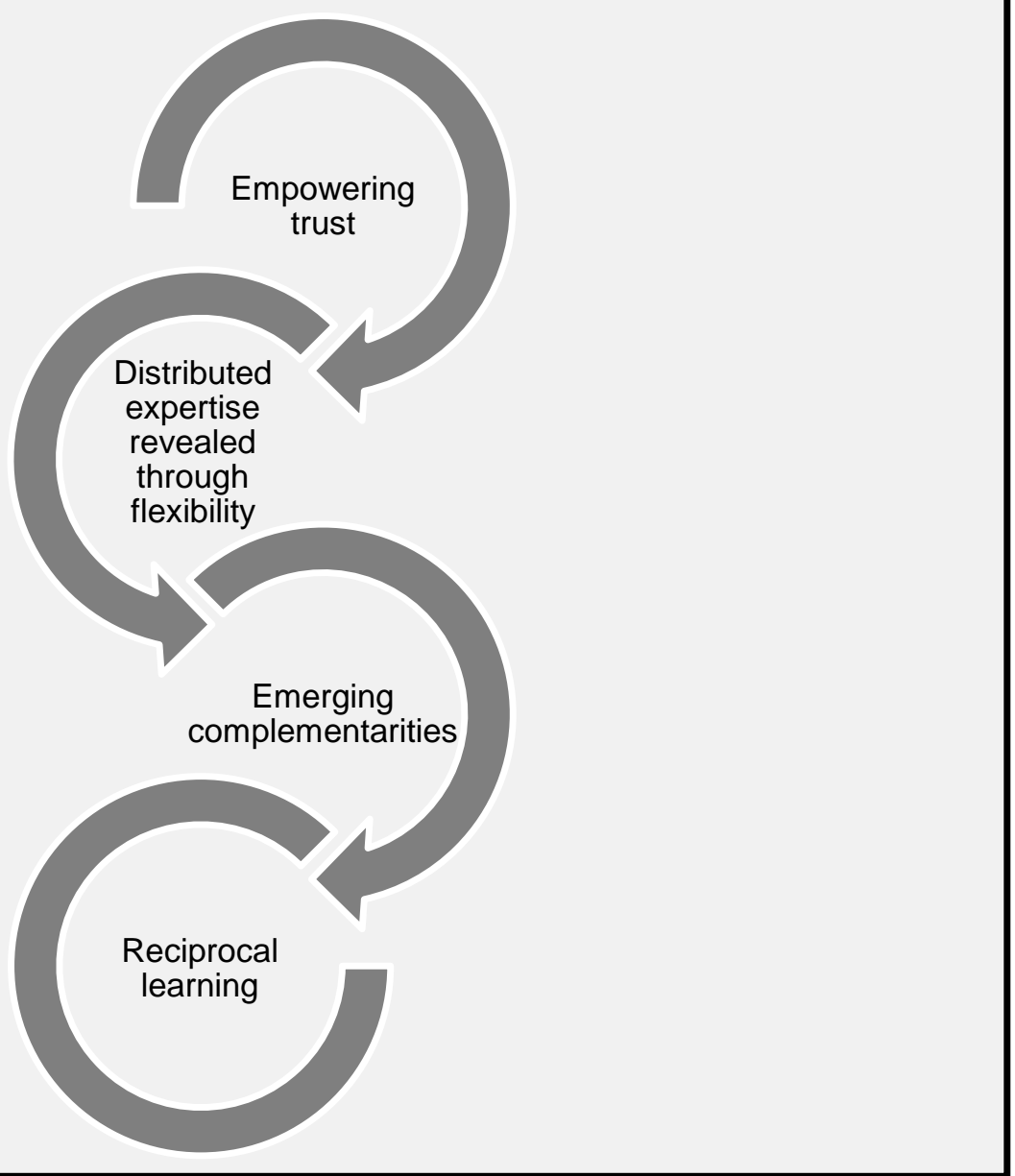

Figure 1: Conceptual framework: The core relationship between trust and reciprocal learning in collaborative projects

A certain degree of distributed expertise stems from the diversity of academic and cultural backgrounds of co-teachers. Even if this distributed expertise pre-exists and precedes the coteaching relationship, it needs to be revealed. Hence, in accordance with Cranston (2011) and Tschannen-Moran (2014), we argue that teachers' complementarities emerge under the conditions of empowering trust, dialogue, and flexibility. Complementarities may emerge as teachers disclose their different competencies, share the decision-making process, and remain flexible in the allocation of their roles in class. Different roles in the course development and delivery can be assigned depending on strengths, preferences, and weaknesses of instructors. As a result, emerging complementarities are made possible by teachers' flexibility and mutual trust which, in return, contribute to reciprocal learning. This conceptual framework was subsequently enriched by our qualitative findings to develop a full model of co-teaching within diversity presented in the findings. 


\section{BACKGROUND AND METHODOLOGY}

As two researchers-practitioners in a South African university, we decided to co-teach a onemonth seminar on research methodology. We thought that our cultural and academic diversity would contribute to creating a rich learning opportunity for our students. Our personal diversity ranged from having different nationalities (French - South African), various academic backgrounds (economics and management - education), diverse teaching experiences (in French and Thai universities - in South African schools and universities), and different degrees in education (Doctor of Education [EdD] - Doctor of Philosophy [PhD]). We also exhibited different personalities which enabled us to complement each other in class. For example, one teacher, who happened to be more extravert, was a charismatic presenter who captivated her audience, while her colleague tended to perform well in answering students' questions thoroughly. Acknowledging and valuing our diversity, we found that our co-teaching experience was an extraordinary opportunity for reciprocal learning and teaching enjoyment.

Regarding the course preparation, we designed the seminar for doctoral and master students in the faculty of education. The seminar included 5 two-hour sessions on different research methodologies. We divided the preparation of sessions based on our strengths and preferences, without dismissing our equal status in class. After agreeing on the content and delivery modes, we located learning materials and worked collaboratively on the presentation slides. We assigned responsibilities between us for the initial draft of sessions based on our content strengths, allowing for a certain degree of flexibility to accommodate our preferences. Prior to each session, the leading course designer finalised the presentation slides, and ensured that both instructors agreed on the course content before entering the classroom.

In class, the main instructor led the session while the secondary instructor added comments and clarifications, provided personal examples, or co-answered students' questions. As each of us took a turn in leading the session, we felt equally recognised. Throughout the delivery of the course, we were happy to acknowledge each other and mindfully shared the teaching space. We found that our spontaneous contributions to the course content were effective in keeping the class lively and thorough, and we believe that the merging of our presentation styles and pedagogical strengths contributed to the class quality.

At the end of the sessions, we kept a reflective journal to record our perceptions of the coteaching experience. Our journal entries were analysed line-by-line against the conceptual framework (Figure 1) in the objective of further enriching it (Lodico, Spaulding and Voegtle 2010). Hence, our conceptualisation of the co-teaching phenomenon occurred iteratively as we wrote, discussed, and coded our reflective journal. Throughout the content thematic analysis of 
our journal entries, we paid particular attention to rigorously include all our contrasted experiences (Creswell 2012). Our findings are presented under the form of a model that aims to set forth the complexity and richness of the co-teaching relationship.

\section{FINDINGS: CONCEPTUALISATION OF THE CO-TEACHING RELATIONSHIP WITHIN DIVERSITY}

Our model of co-teaching within diversity (Figure 2) enlightens the productive outcomes that result from the confrontation of expertise and practices. This model of co-teaching enabled us to answer the two research questions as it retrospectively conceptualises our co-teaching experience and elicits the disruptive experience and growth merits of the co-teaching experience within diversity.

This model ought to embrace diverse situations and does not only cater for our idiosyncratic experiences. We drew on the literature on co-teaching (Brooks and Brooks 2015; Ferguson and Wilson 2011; Graziano and Navarrete 2012; Plank 2011) and used it to inform and enrich the model. With regard to the model's generalisation, we used a scaffolding strategy drawing on the literature results and our findings to increase the model's relevance for diverse co-teaching contexts.

Three broad issues are associated with the experience of co-teaching within diversity. First is the negotiation of roles which occurs ideally in a context of empowering trust, flexibility, and a disclosure of distributed expertise. This is followed by the operationalisation of complementarities in the act of teaching, including spontaneous contributions in class. The third and last step is the disruptive and productive professional development that stems from $i$. reciprocal learning and ii. professional identity affirmation. Reciprocal learning arises from the in vivo exposure to the pedagogical practices of one's colleague, including “aha” moments, while the affirmation of competency and professional identity is made possible through the covalidation of each other's knowledge in the course preparation and delivery. In the following paragraphs, we elaborate on these stages before discussing the disruptive learning opportunities offered by co-teaching in a context of diversity.

\section{Planning and preparation}

\section{Empowering trust}

Our complementarities emerged under the guidance of empowering trust, flexibility, and dialogue. The trusting atmosphere we created was instrumental in enabling us to share the 
decision-making process. Empowering trust is achieved through constant dialogue, and enables instructors to share their strengths and weaknesses in a collegial environment. The success of the preparation phase requires reciprocal trust in the ability and desire of both teachers to contribute to the quality of the course, and to do it on time. In our co-teaching experience, the structure of the course and the active learning approach had been discussed and agreed on. We negotiated the content of the seminar and let our complementarities emerge throughout the planning and delivery phases.

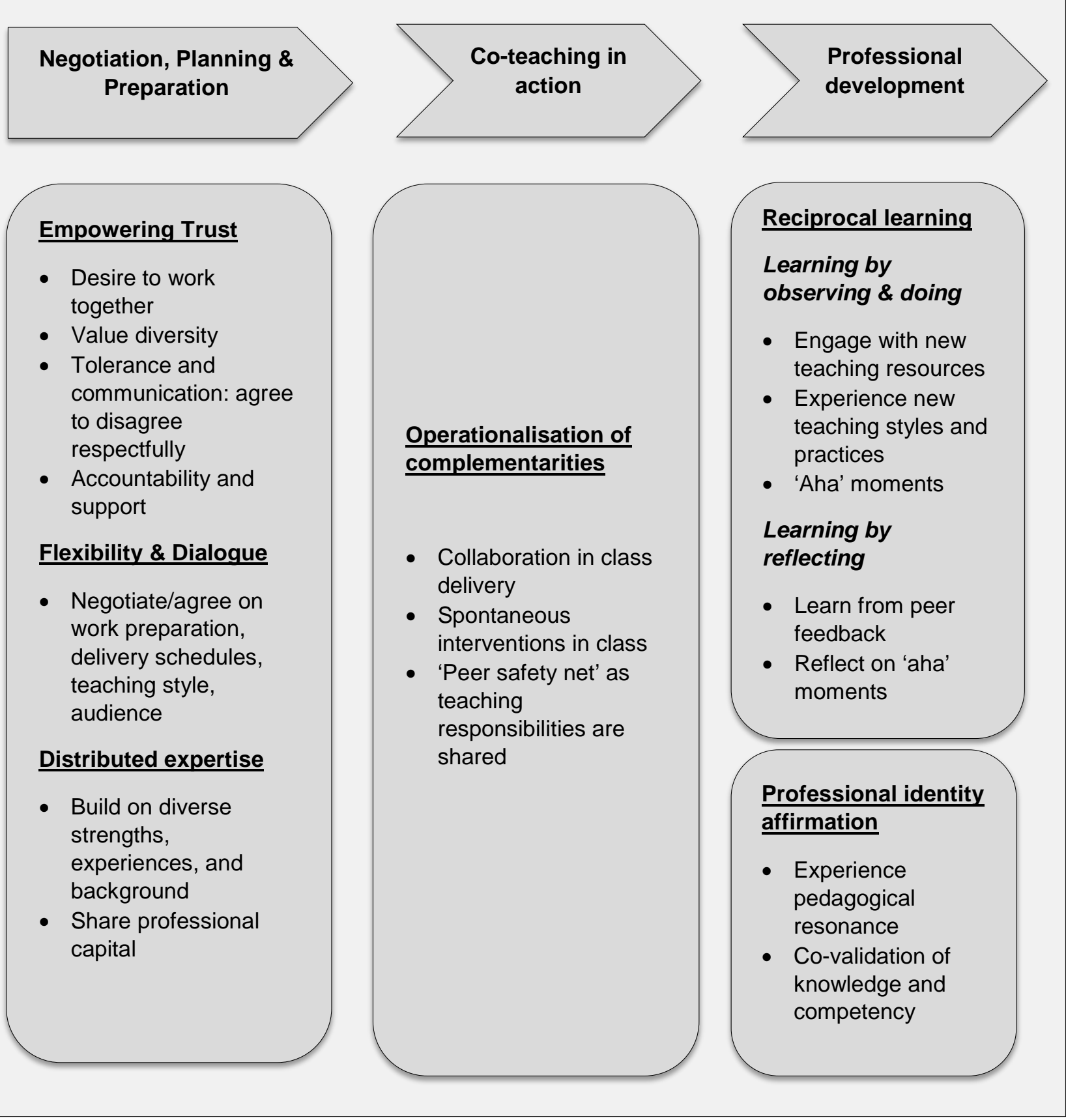

Figure 2: The model of co-teaching within diversity: Stages and benefits 
We also believed that maintaining an equal status in class was an important element of our trust building strategy as it minimised the risks of power and recognition competition in class. We felt mutually accountable for the class success and responsibility. Hence, some complementarities arose without anticipating them, as we felt our diverse competencies and viewpoints were mutually valued.

\section{Flexibility and dialogue}

Our complementarities emerged as we intentionally remained flexible to adjust to each other's strengths and preferences. For example, the statistical background of one teacher enabled her to develop the quantitative session even though she would have enjoyed taking the lead in the qualitative session. We also used two methods to prepare the presentation slides. One teacher searched for tables, charts, and pictures to illustrate and contrast the course notions, while another listed key terms and structured them in accordance with the course syllabus. We reconciled both approaches by discussing different ways of presenting the learning materials. The outcome, we think, was a well-structured and engaging class that contributed to student engagement. Furthermore, we openly challenged our own perceptions during the course preparation and we reported in class how we shared different opinions and negotiated meanings and understandings. By doing so, we wanted to model for our students ways of interfacing our different perspectives toward constructing relevant knowledge.

\section{Distributed expertise}

Diversity brings about distributed expertise in content and pedagogical knowledge that needs to be revealed. This distributed expertise encompasses teachers' specific strengths, knowledge, and competencies that can be summarised in professional capital. Professional capital is derived from the various backgrounds and experiences of faculty members. For example, host teachers can better understand the local context including students' needs and expectations, while international lecturers can bring different teaching practices and perspectives to the class.

To reap the benefits of this distributed expertise, empowering trust, flexibility, and dialogue were crucial requisites. They enabled complementarities to emerge in the course preparation. In addition, the clarification of roles and meanings in the preparation phase was important to smooth the delivery of the collaborated sessions and operationalise teachers' complementarities in class.

\section{Co-teaching in action: The operationalisation of complementarities}

A well-negotiated preparation sets the pace for an effective class delivery. Co-teaching is a 
dynamic process: its challenge is to maintain a balance in the space allocated to each teacher. It requires teachers to be mindful of their colleagues' space to enable them to expose their ideas and perspectives in class. The fluidity of co-teaching is enhanced by prior session planning, but also by the desire of both teachers to value the spontaneous contributions of their peer colleagues in front of students.

During the class, teachers can rely on each other and operationalise the full scope of their complementarities. For example, we complemented each other in class through spontaneous comments to scaffold or deepen the class discussions. In addition, co-teaching reduces the stress level and provides a safety net to answer students' questions with accuracy, as also highlighted in literature (Birrell and Bullough Jr. 2005; Ferguson and Wilson 2011). More specifically, what is presented in class by a first teacher is backed up by the knowledge of the second. In our case, a teacher highlighted that she was reassured by her colleague's ability to contribute to the explanations, while the other admired how her colleague uplifted the discussion with quotations and engaged the class discussion with cartoon pictures. She expressed her desire to use similar teaching artefacts in preparing future sessions. As described below, co-teachers can observe each other in class and learn mutually through interfacing their distinctive knowledge and practices, while reflecting on their own practice.

\section{Reciprocal learning}

Co-teaching is a catalyst for pedagogical learning if each instructor can teach as she thinks is best, enabling her peer colleague to observe different practices. However, it requires that no teacher imposes one way of doing. Each teacher brings idiosyncratic experiences and tacit knowledge that will be revealed during the actual teaching. This tacit job-embedded knowledge is unfolded in the classroom, which offers a unique opportunity for co-teachers to learn by observing. In addition to observing, team teaching enables colleagues to experiment with new activities and experience "aha” moments. Reciprocal learning arises from opportunities to observe and experiment with a colleague's ways of teaching but also to reflect on personal teaching habits. It can result in incremental to disruptive reciprocal learning.

In accordance with experiential (Kolb and Kolb 2005) and transformative learning theories (Mezirow 2012), co-teachers experience different pedagogical practices in class that enable them to reflect on their current weaknesses and derive strategies for future teaching. Coteaching exposes instructors to new practices that they may have previously ignored (Graziano and Navarrete 2012; Luke and Rogers 2015). They encounter novelty with opportunities to experience dissonance and "aha" moments. This dissonance is also referred to as disorienting 
dilemma in the transformative learning theory (Mezirow 2012), and thus enables co-teachers to grow professionally.

Such an example of transformative learning occurred in our co-teaching experience, when a disruption emerged in the confrontation of our taken-for-granted assumptions with regards to the research paradigms. We were taught in different countries, with different training and experiences, so it was not a surprise that we would be teachers with different perspectives and teaching styles. However, clarifying to each other our different points of view enabled us ultimately to see through different paradigms. Our relationship, based on empowering trust, allowed us to "agree to disagree” respectfully.

Another example of a disruptive experience occurred at the end of the co-teaching partnership when we decided to write collaboratively about our teaching collaboration. This disruption arose because we did not share in advance our conceptions of what the co-writing work entailed. We thought that the process would smoothly follow on our positive co-teaching experience. However, our expectations were not explicit with regards to the roles of the first and the second author. Hence, as our expectations diverged, we became frustrated with the process. This conflict revealed our different perceptions of what co-authoring meant and how renegotiable previous agreements were. To maintain our trusting relationship, we had to voice our concerns and redefine the role boundaries of the first and second authors towards reaching a mutually satisfying agreement. This disorienting dilemma enabled us to understand that the conceptions of co-writing differ widely in a way we had surely underestimated. It raised our awareness of the different ways of doing and encouraged us to better clarify our implicit expectations. Hence, strengthened by this experience, we decided to co-author an additional article for which we swapped first authorship.

Finally, both teachers learned different practices through the exposure to new activities: One teacher observed how to manage group discussions timely and effectively, while another learned how to use life-related metaphors to illustrate the course. For example, one observed how her colleague drew analogies between the research process and the shopping experience at a flea market to enlighten the decision-making process. After the class, colleagues had the opportunity to provide feedback that encouraged the self-reflection process of co-teachers and could contributed to strengthening their feeling of professional competency.

\section{Professional identity affirmation}

Contrary to the experience of dissonance mentioned earlier, instructors can experience pedagogical resonance with their colleague. Experiencing resonance happens when lecturers 
share the same pedagogical approaches or a desire to implement similar learning activities. Experiencing resonance in knowledge and teaching habits enables lecturers to feel comforted in their practices as it strengthens their sense of competency and self-efficacy (Prud'homme and Bergeron 2015). It contributes to reinforcing their professional identity (Clement and Vandenberghe 2000).

As teachers prepare and teach the class together, their knowledge is peer-validated before being exposed to students. This co-validation of the course content strengthens their sense of knowledge competency (Jeannin 2017). In our experience, we cross-validated our knowledge in philosophical paradigms during the class preparation, and we shared the same participative teaching approach using Think-Pair-Share activities.

Finally, co-teaching can enable lecturers to overcome the imposter phenomenon (Luke and Rogers 2015; Clance and Imes 1978) as it strengthens their sense of competency and selfesteem in a mutually safe environment. Being recognised by colleagues helps build confidence in one's own intellectual capacities and self-efficacy. It forces co-instructors to realise that they are not “imposters" (Luke and Rogers 2015, 255) and that they fully contribute to the knowledge creation and dissemination.

As a result, reciprocal learning and professional identity affirmation are the two prominent advantages of co-teaching within diversity and together contribute to co-teachers' professional development. Growing professionally from the co-teaching experience however presupposes that peer instructors manage to navigate through the risks of ego-related issues and crosscultural misunderstandings.

\section{THEORETICAL AND PRACTICAL IMPLICATIONS}

As it highlights key factors and conditions of reciprocal learning, the model contributes to the conceptualisation of co-teaching in a context of academic and cultural diversity. In accordance with the research problem identified in the introduction, our model can help host and international lecturers develop effective co-teaching strategies. It sets forth the key components and phases of the co-teaching process, and can guide teachers along the risky but high-return journey of team teaching in culturally diverse contexts, in South African universities for instance.

We argue that the learning resulting from co-teaching within diversity has the potential to be disruptive as it exposes lecturers to practices and activities they would not have otherwise used. The disruptive aspects of co-teaching can be analysed through two lenses: Firstly, teachers have to take risks and go beyond their comfort zone. They are made vulnerable to peer 
judgement as they expose their content and pedagogical knowledge to their colleague. Secondly, the exposure to dissonance and disorienting dilemmas may generate disruptive professional learning (Mezirow 2012). For example, co-teachers experience dissonance when they are exposed to an activity in class they would not have encountered otherwise. They are confronted by different teaching paradigms and practices. These disorienting dilemmas may trigger dialogues and further research, leading to an expansion of pedagogical frames of reference (Mezirow 2012) and professional growth.

The role of exposure to diversity in generating professional learning is also reported across the co-teaching literature with diverse faculty members (Ferguson and Wilson 2011; Graziano and Navarrete 2012; Plank 2011). Co-teaching produces embedded professional development as teachers learn by doing and by reflecting with the help of knowledgeable colleagues (Shaffer and Thomas-Brown 2015; Prud'homme and Bergeron 2015). This study contributes to the current debates in South Africa pertaining to the opportunities for host and international staff to collaborate and generate new knowledge (Cross, Mhlanga and Ojo 2009; Kishun 2007). It also fits into the analysis of the opportunities and challenges created by the internationalisation of the academic staff population worldwide (Bauder 2015; Lai, Li and Gong 2016; Mizzi 2017; Spencer-Oatey 2013).

As Lai, Li and Gong (2016) advanced, we maintain that international collaboration reveals its full potential under the condition that host and international lecturers are invited to collaborate. Diverse faculty members can generate new ideas and practices if their collaboration enables them to share their professional capital, reveal their tacit job-embedded knowledge, and operationalise their complementarities creatively (Graziano and Navarrete 2012; Lai, Li and Gong 2016). As lecturers interface their skills and experiences, the professional development that results from co-teaching may be contextualised (Leibowitz, Vorster, and Ndebele 2016) and thus, tailored to the specific learning needs of students in South African universities. In addition to reciprocal learning, the inspiration and motivation ensuing from faculty collaboration can support teachers' commitment and positively impact their teaching effectiveness (Day 2008; Pyhältö, Pietarinen and Soini 2015). Hence, universities should encourage diverse faculty members to learn from each other and overcome the challenges of intercultural collaboration (Spencer-Oatey 2013).

\section{LIMITATIONS}

Our conceptual model was derived from our co-teaching experience and the current debates in the literature. Our self-reflective approach enabled us to engage in sustained dialogues and 
deepen our understanding of the co-teaching relationship. We acknowledge however that the phenomenon of co-teaching is influenced by a variety of factors that include, among others, the institutional and managerial cultures of the site, the teaching framework, the student population, and the availability of resources to fund co-teaching. All co-teaching relationships are peopleand context-specific and it implies, as a limitation, that the model cannot encompass all of them. It however provides a framework that can guide faculty members by creating an awareness of the stages, conditions of success, and advantages of co-teaching within diversity.

Finally, we acknowledge that this article does not include students' perceptions of the cotaught class. Their perceptions may be different from teachers' experiences as noted by Luke and Rogers (2015). When asked, our students reported positive feedback about the seminar, but the data we have are too little to draw any conclusion regarding their perceptions.

\section{CONCLUSION}

The article presented the reflections of two diverse researchers-practitioners on their coteaching experiences in a South African university. It conceptualised their co-teaching experiences, eliciting the stages and learning advantages of co-teaching within cultural and academic diversity. This article contributes to the current debate on host and international academic collaboration as a result of universities' internationalisation and academic staff mobility, not only in South Africa. It provides a model of co-teaching that can guide productive collaborations among diverse academics.

We used our findings and the current literature to develop a model of co-teaching within diversity. In this model, co-teaching was conceptualised around the phases of course preparation, the operationalisation of complementarities, reciprocal learning, and professional identity affirmation. It highlighted the prevalence of empowering trust and flexibility to reap the benefits of distributed expertise in a context of cultural diversity.

We argued that co-teaching creates opportunities for disruptive professional learning as it enables lecturers to venture beyond their comfort zone, take risks collectively, and encounter new pedagogical practices. It exposes co-instructors to dissonance and novelty, especially in a cross-cultural context. It also supports the development of their professional identity through the experiences of resonance and the co-validation of their content and pedagogical competencies. Hence, to support reciprocal learning and lecturers' self-competency, the administration of universities should encourage faculty members to partake in co-teaching while remaining open to diverse ways of teaching and learning. 


\section{REFERENCES}

Bauder, Harald. 2015. The international mobility of academics: A labour market perspective. International Migration 53(1): 83-96. doi:10.1111/j.1468-2435.2012.00783.x.

Birrell, James R. and Robert V. Bullough Jr. 2005. Teaching with a peer: A follow-up study of the 1st year of teaching. Action in Teacher Education 27(1): 72-81. doi:10.1080/01626620.2005.10463375.

Brett, Jeanne, Kristin Behfar and Mary C. Kern. 2006. Managing multicultural teams. Harvard Business Review 84(11): 85-98.

Brooks, Melanie C. and Jeffrey S. Brooks. 2015. Exploring opportunities and challenges of crosscultural and international teaching, research, and service for higher education faculty members. In Cross-cultural collaboration and leadership in modern organization, ed. Nancy Erbe and Anthony Normore, 35-48. IGI Global.

Clance, Pauline R. and Suzanne A. Imes. 1978. The imposter phenomenon in high achieving women: Dynamics and therapeutic intervention. Psychotherapy: Theory, Research \& Practice 15(3): 241. doi:10.1037/h0086006.

Clement, Mieke and Roland Vandenberghe. 2000. Teachers' professional development: A solitary or collegial (ad)venture? Teaching and Teacher Education 16(1): 81-101. doi:10.1016/S0742051X(99)00051-7.

Cook, Lynne and Marilyn Friend. 1995. Co-teaching: Guidelines for creating effective practices. Focus on Exceptional Children 28(3): 1-16.

Cranston, Jerome. 2011. Relational trust: The glue that binds a professional learning community. Alberta Journal of Educational Research 57(1): 59-72. http://www.ajer.ca/

Creswell, John W. 2012. Educational research: Planning, conducting, and evaluating quantitative and qualitative research. Boston, MA: Pearson Education.

Cross, Michael, Ehpraim Mhlanga and Emmanuel Ojo. 2009. Emerging concept of internationalisation in South African higher education: Conversations on local and global exposure at the University of the Witwatersrand (Wits). Journal of Studies in International Education 15(1): 75-92. doi:10.1177/1028315309334635.

Day, Christopher. 2008. Committed for life? Variations in teachers' work, Lives and effectiveness. Journal of Educational Change 9(3): 243-60. doi:10.1007/s10833-007-9054-6.

Dunn, Lee and Michelle Wallace. (Eds.). 2008. Intercultural communities of practice. In Teaching in transnational higher education: Enhancing learning for offshore international students. New York, NY: Routledge. http://epubs.scu.edu.au/gcm_pubs/44/

Encabo, Mary. 2015. Developing “middle” pedagogy. Teaching and Learning Together in Higher Education 1(14): 1-5.

Ferguson, Jacqueline and Jenny C. Wilson. 2011. The co-teaching professorship: Power and expertise in the co-taught higher education classroom. Scholar-Practitioner Quarterly 5(1): 52-68.

Graziano, Kevin J. and Lori A. Navarrete. 2012. Co-teaching in a teacher education classroom: Collaboration, compromise, and creativity. Issues in Teacher Education 21(1): 109-126.

Hersi, Afra Ahmed, Deborah A. Horan and Mark A. Lewis. 2016. Redefining "community” through collaboration and co-teaching: A case study of an ESOL specialist, a literacy specialist, and a fifth-grade teacher. Teachers and Teaching: Theory and Practice 22(8): 927-946. doi:10.1080/13540602.2016.1200543.

Hsieh, Betina and HuongTran Nguyen. 2015. Co-teaching, co-leading, co-learning: Reflection on the 
co-teaching model in practicum. Teaching and Learning Together in Higher Education 1(14): $1-9$.

Hurd, Ellis. 2016. Using co-teaching as professional development for middle level teacher candidates, cooperating teachers, and university faculty. In The 7th Pacific Rim Conference on Education. Illinois State University. http://ir.library.illinoisstate.edu/pacrim/2017/

Jeannin, Loïse. 2017. L'enseignement partagé comme source de développement professionnel. Apprentissage transformatif et renforcement de l'identité professionnelle. Carnets de recherche sur la formation. https://crf.hypotheses.org/85

Jowi, James Otieno. 2012. African universities in the global knowledge economy: The good and ugly of internationalization. Journal of Marketing for Higher Education 22(1): 153-165. doi:10.1080/08841241.2012.705799.

Kainzbauer, Astrid and Brian Hunt. 2014. Meeting the challenges of teaching in a different cultural environment: Evidence from graduate management schools in Thailand. Asia Pacific Journal of Education 36: 1-13. doi:10.1080/02188791.2014.934779.

Kishun, Roshen. 2007. The internationalisation of higher education in South Africa: Progress and challenges. Journal of Studies in International Education 11(3-4): 455-469. doi:10.1177/1028315307304184.

Kolb, Alice and David Kolb. 2005. Learning styles and learning spaces: Enhancing experiential learning in higher education. Academy of Management Learning \& Education 4(2): 193-212. doi:10.5465/AMLE.2005.17268566.

Lai, Chun, Zhen Li and Yang Gong. 2016. Teacher agency and professional learning in cross-cultural teaching contexts: Accounts of Chinese teachers from international schools in Hong Kong. Teaching and Teacher Education 54: 12-21. doi:10.1016/j.tate.2015.11.007.

Le Grange, Lesley. 2016. Decolonising the university curriculum. South African Journal of Higher Education 30(2): 1-12. doi:10.20853/30-2-709.

Leibowitz, B. L., J. Vorster and C. Ndebele. 2016. Why a contextual approach to professional development? South African Journal of Higher Education 30(6): 1-7. doi:10.20853/30-6-714.

Lodico, Marguerite G., Dean T. Spaulding and Katherine H. Voegtle. 2010. Methods in educational research: From theory to practice. Vol. 28. San Francisco, CA: Jossey-Bass.

Luke, Nancy and Carrie Rogers. 2015. Responding to uncertainty: Teacher educator professional development through co-teaching and collaborative reflection. LEARNing Landscapes 8(2): 245-260.

Ma, Wen. 2014. East meets West in teacher preparation: Crossing Chinese and American borders. New York, NY: Teachers College Press.

Martin-Beltran, Melinda and Megan Madigan Peercy. 2014. Collaboration to teach English language learners: Opportunities for shared teacher learning. Teachers and Teaching: Theory and Practice 20(6): 721-737. doi:10.1080/13540602.2014.885704.

Merriam, Sharan B. and Young Sek Kim. 2011. Non-Western perspectives on learning and knowing. In The Jossey-Bass Reader on contemporary issues in adult education, ed. Sharan B. Merriam and Andre P. Grace, 378-390. San Francisco, CA: Jossey-Bass.

Mezirow, Jack. 2012. Learning to think like an adult: Core concepts of transformation theory. In The handbook of transformative learning: Theory, research, and practice, ed. Edward W. Taylor and P. Cranton, 73-95. San Francisco, CA: John Wiley \& Sons.

Mizzi, Robert C. 2017. Bridging borders: Toward a pedagogy of preparedness for visiting faculty. Journal of Studies in International Education, 1-15. doi:10.1177/1028315316687011.

Plank, Kathryn M. 2011. Team teaching: Across the disciplines, across the academy. Sterling, VI: Stylus 
Publishing, LLC.

Prud'homme, Luc and Geneviève Bergeron. 2015. Diversité, Étude de Soi et Engagement Professionnel En Formation Initiale À L'enseignement. In Mutations Éducatives et Engagement Professionnel, ed. France Merhan, Anne Jorro and Jean-Marie De Ketele. Perspectives En Éducation et Formation. Louvain-la-Neuve, BE: De Boeck Supérieur.

Pyhältö, Kirsi, Janne Pietarinen and Tiina Soini. 2015. Teachers’ professional agency and learning from adaption to active modification in the teacher community. Teachers and Teaching: Theory and Practice 21(7): 811-30. doi:10.1080/13540602.2014.995483.

Rouhani, Sepideh. 2007. Internationalisation of South African higher education in the postapartheid era. Journal of Studies in International Education 11(3-4): 470-485. doi:10.1177/1028315307304185.

Shaffer, LaShorage and Karen Thomas-Brown. 2015. Enhancing teacher competency through coteaching and embedded professional development. Journal of Education and Training Studies 3(3): 117-25. doi:10.11114/jets.v3i3.685.

Smith, Karen. 2009. Transnational teaching experiences: An under-explored territory for transformative professional development. International Journal for Academic Development 14(2): 111-122. doi:10.1080/13601440902969975.

Spencer-Oatey, Helen. 2013. Maximizing the benefits of international education collaborations managing interaction processes. Journal of Studies in International Education 17(3): 244-261. doi:1028315312454545.

Tadaki, Marc and Christopher Tremewan. 2013. Reimagining internationalization in higher education: International consortia as a transformative space? Studies in Higher Education 38(3): 367-387. doi:10.1080/03075079.2013.773219.

Tschannen-Moran, Megan. 2014. Trust matters: Leadership for successful schools. 2nd Edition. San Francisco, CA: John Wiley \& Sons.

Volet, Simone and Cheryl Jones. 2012. Cultural transitions in higher education: Individual adaptation, transformation and engagement. In Transitions across schools and cultures, ed. Stuart Karabenick and Timothy Urdan, 17: 241-284. Advances in Motivation and Achievement. Bingley: Emerald Group Publishing Limited. 